\title{
Hyperparathyroidism, CTCAE
}

National Cancer Institute

\section{Source}

National Cancer Institute. Hyperparathyroidism, CT CAE. NCI Thesaurus. Code C143557.

A disorder characterized by an increase in production of parathyroid hormone by the parathyroid glands. This results in hypercalcemia (abnormally high levels of calcium in the blood). 